\title{
Occult dysplasia in a localized giant pseudopolyp in Crohn's colitis: A case report
}

\author{
Jonathan Wyse MD FRCPC ${ }^{1}$, Esther Lamoureux MD FRCPC ${ }^{2}$, \\ Philip H Gordon MD FRCSC FACS ${ }^{3}$, Alain Bitton MD FRCPC ${ }^{1}$
}

\begin{abstract}
J Wyse, E Lamoureux, PH Gordon, A Bitton. Occult dysplasia in a localized giant pseudopolyp in Crohn's colitis: A case report. Can J Gastroenterol 2009;23(7):477-478.
\end{abstract}

Localized giant pseudopolyposis of the colon (pseudopolyp larger than $1.5 \mathrm{~cm}$ in size) is a rare complication of inflammatory bowel disease. There is one report of an occult carcinoma within such a lesion, and no reports of sole dysplasia. A case of a 42-year-old man with longstanding Crohn's colitis who underwent a colonoscopy revealing a large, multilobulated mass at the splenic flexure that was not amenable to endoscopic removal, is described. Multiple biopsies showed no dysplasia and histology was consistent with an inflammatory pseudopolyp. Computed tomographic colonography demonstrated a mass resembling a large villous tumour. A decision for surgery was made. The surgical specimen was a complex anastomosing inflammatory pseudopolyp $5 \mathrm{~cm} \times 4 \mathrm{~cm} \times 3 \mathrm{~cm}$ in size, with a focus of low-grade dysplasia in an area free of inflammation.

The present case is the first reported occult dysplasia in a giant pseudopolyp. Occult dysplasia without superficial dysplasia may exist in these lesions and further studies are needed to examine risk factors that make a giant pseudopolyp more likely to harbour dysplasia and/or carcinoma.

Key Words: Crohn's colitis; Dysplasia; Inflammatory; Occult; Pseudopolyp

Tnflammatory polyps (pseudopolyps) are formed in the regenerative and healing phases of ulcerated epithelium and are deemed to have no intrinsic malignant potential $(1,2)$. Localized giant pseudopolyposis of the colon is a rare complication of inflammatory bowel disease (IBD), defined as a pseudopolyp (isolated or clustered) larger than $1.5 \mathrm{~cm}(3,4)$. There are more than 75 reported cases in the literature (3-20), but only one report of an occult carcinoma associated with such a lesion (20) and no reports of associated dysplasia. A case of a giant pseudopolyp containing occult dysplasia in the absence of adenomatous tissue in a patient with Crohn's colitis is presented.

\section{CASE PRESENTATION}

A 42-year-old man with longstanding Crohn's colitis in remission, presented with a two-month history of nonbloody diarrhea. A colonoscopy revealed scattered diminutive pseudopolyps in the left colon and a large multilobulated mass at the splenic flexure that was not amenable to endoscopic resection. Biopsies revealed histology consistent with an inflammatory pseudopolyp. The patient was treated with oral antibiotics and mesalamine for active Crohn's colitis.

A repeat colonoscopy three months later revealed few erosions; histology of the unchanged polypoid mass was again

\section{Dysplasie occulte dans un pseudopolype localisé géant en présence de colite de Crohn : Rapport de cas}

\begin{abstract}
La pseudopolypose géante localisée au côlon (pseudopolype de plus de $1,5 \mathrm{~cm}$ de diamètre) est une complication rare de la maladie inflammatoire de l'intestin. Un rapport a mentionné un carcinome occulte dans une telle lésion, mais il n'existe aucun rapport de dysplasie isolée. On décrit ici le cas d'un homme de 42 ans souffrant de colite de Crohn de longue date, dont la coloscopie a révélé une masse multilobulaire volumineuse au niveau de l'angle splénique ne pouvant être excisée par endoscopie. Plusieurs biopsies ont révélé l'absence de dysplasie et l'histologie concordait avec un pseudopolype inflammatoire. La colonographie assistée par ordinateur a révélé une masse ressemblant à une volumineuse tumeur villeuse. Une chirurgie s'imposait. L'échantillon chirurgical était un pseudopolype inflammatoire anastomosé complexe d'une dimension de $5 \mathrm{~cm} \times 4 \mathrm{~cm} \times 3 \mathrm{~cm}$, mettant l'accent sur une dysplasie de faible intensité dans un foyer sans inflammation.

Il s'agit du premier cas rapporté de dysplasie occulte dans un pseudopolype géant. La dysplasie occulte, sans dysplasie superficielle, peut exister dans ces lésions et d'autres études sont requises pour analyser les facteurs de risque qui rendent un pseudopolype géant plus susceptible d'héberger une dysplasie et/ou un cancer
\end{abstract}

\footnotetext{
${ }^{1}$ Division of Gastroenterology, McGill University Health Centre, ${ }^{2}$ Department of Pathology, Jewish General Hospital, McGill University,

${ }^{3}$ Division of Colorectal Surgery, Sir Mortimer B Davis Jewish General Hospital, McGill University, Montréal, Québec.

Correspondence: Dr Alain Bitton, Royal Victoria Hospital, 687 Pine Avenue West, Montréal, Québec H3A 1A1.

Telephone 514-843-1616, fax 514-843-1421, e-mail alain.bitton@muhc.mcgill.ca

Received and accepted for publication June 10, 2008
} 


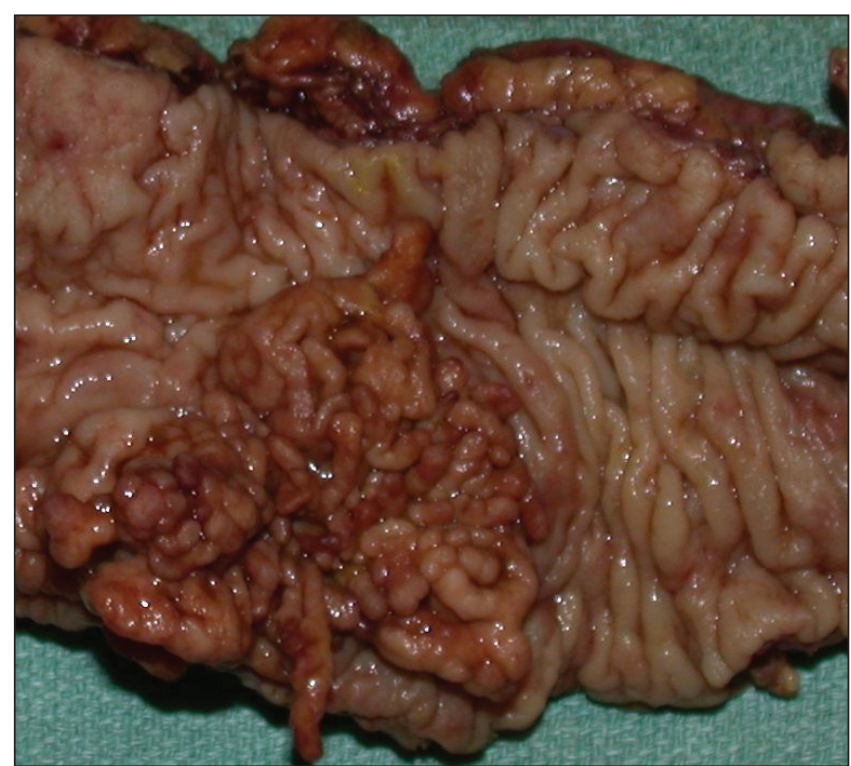

Figure 1) Gross surgical specimen demonstrating a giant inflammatory pseudopolyp $5 \mathrm{~cm} \times 4 \mathrm{~cm} \times 3 \mathrm{~cm}$ in size

area free of active inflammation, a few glands revealed severe epithelial atypia, namely, nuclear hyperchromatism, crowding disorganization and stratification, qualifying for low-grade dysplasia. This opinion was shared by two additional gastrointestinal pathologists. The lymph nodes were negative for malignancy.

\section{DISCUSSION}

Localized giant pseudopolyposis is a well-documented although uncommon occurrence in IBD (3-20). It has been described in both active and quiescent phases of disease, in all colonic segments and tends to occur early in the course of IBD $(3,10-12)$. Clinical symptoms are not usually related to the lesion but rather to disease activity itself, although colonic obstruction and intussusception have been reported $(16,19)$.

Clinically, endoscopically and radiologically, these masses have commonly been mistaken for neoplastic lesions $(3,11,12$, $15,17,21)$. The dilemma revolves around confidently differentiating a giant pseudopolyp from a villous adenoma, dysplasiaassociated lesion or mass, or polypoid carcinoma. The differential diagnosis also includes lymphoma and colitis cystica profunda $(3,11,12)$.

Notwithstanding one report (20) of an occult malignancy arising in a giant pseudopolyp in ulcerative colitis, previous authors have suggested that colonoscopy with multiple biopsies will demonstrate the nature of the lesion and is considered sufficient to establish a diagnosis and avoid surgery (3,10,15-17). Surgery remains indicated for large lesions that are incompletely visualized or inadequately biopsied $(3,11,15)$.

The first case of a giant pseudopolyp in Crohn's colitis complicated by dysplasia is described. Importantly, the dysplasia was not identified on superficial endoscopic biopsies but rather in the surgical specimen. This suggests that the benign nature of these lesions should not be assumed. It remains unclear whether specific factors such as patient age, size of the lesion, or the duration or activity of the patient's disease make a localized giant pseudopolyp more likely to harbour dysplasia. The natural history of these lesions, as well as their optimal management, remain uncertain. Radiological imaging can define the location and extent, but not the nature of these lesions. Until further data are available, when assessing giant pseudopolyps for occult dysplasia or adenocarcinoma, an individualized approach based on the patient's disease characteristics, preferences and surgical candidacy is recommended.

11. Ooi BS, Tjandra JJ, Pedersen JS, et al. Giant pseudopolyposis in inflammatory bowel disease. Aust N Z J Surg 2000;70:389-93.

12. Hinrichs HR, Goldman H. Localized giant pseudopolyps of the colon. JAMA 1968;205:248-9.

13. Joffe N. Localised giant pseudopolyposis secondary to ulcerative or granulomatous colitis. Clin Radiol 1977;28:609-16.

14. Goldgraber MB. Pseudopolyps in ulcerative colitis. Dis Colon Rectum 1965;5:355-63.

15. Ferguson CJ, Balfour TW, Padfield CJ. Localized giant pseudopolyposis of the colon in ulcerative colitis. Report of a case. Dis Colon Rectum 1987;30:802-4.

16. Fitterer JD, Cromwell LG, Sims JE. Colonic obstruction by giant pseudopolyposis. Gastroenterology 1977;72:153-6.

17. Katz S, Rosenberg RF, Katzka I. Giant pseudopolyps in Crohn's colitis. A nonoperative approach. Am J Gastroenterol 1981;76:267-71.

18. Teague RH, Read AE. Polyposis in ulcerative colitis. Gut $1975 ; 16: 792-5$

19. Forde KA, Gold RP, Holck S, et al. Giant pseudopolyposis in colitis with colonic intussusception. Gastroenterology 1978;75:1142-6.

20. Kusunoki M, Nishigami T, Yanagi H, et al. Occult cancer in localized giant pseudopolyposis. Am J Gastroenterol 1992;87:379-81.

21. Fishman RS, Fleming CR, Stephens DH. Roentgenographic simulation of colonic cancer by benign masses in Crohn's colitis. Mayo Clin Proc 1978;53:447-9. 


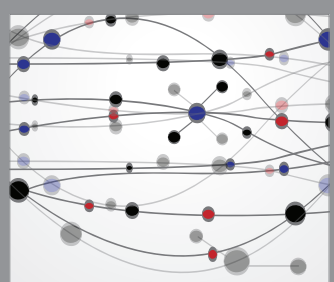

The Scientific World Journal
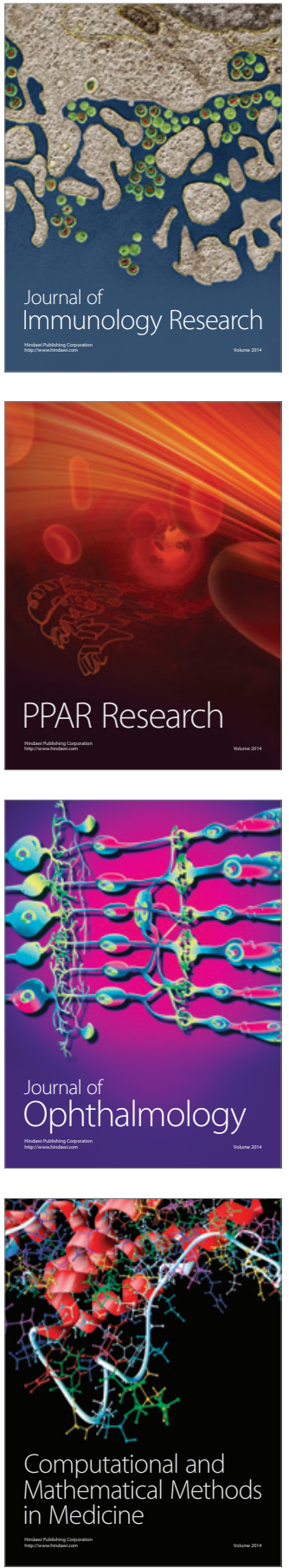

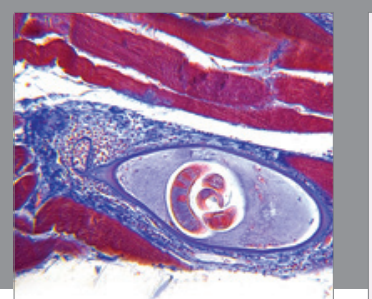

Gastroenterology Research and Practice

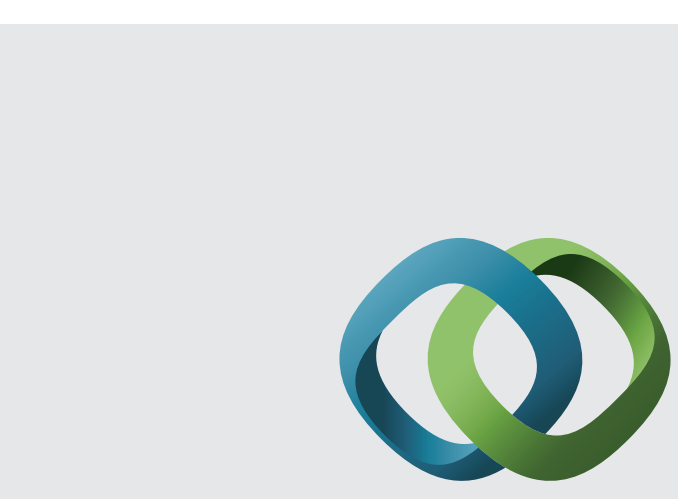

\section{Hindawi}

Submit your manuscripts at

http://www.hindawi.com
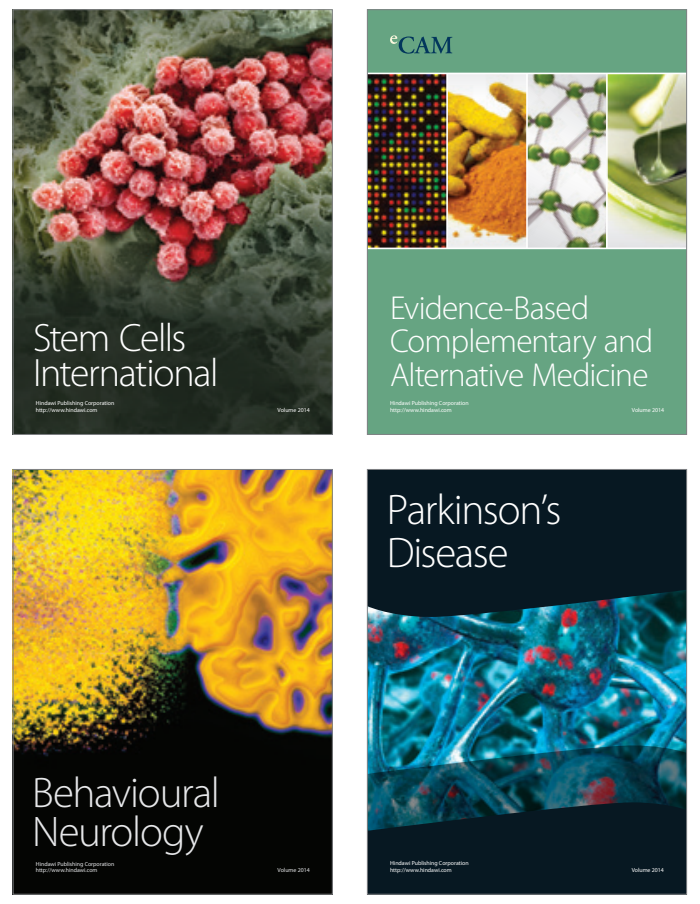
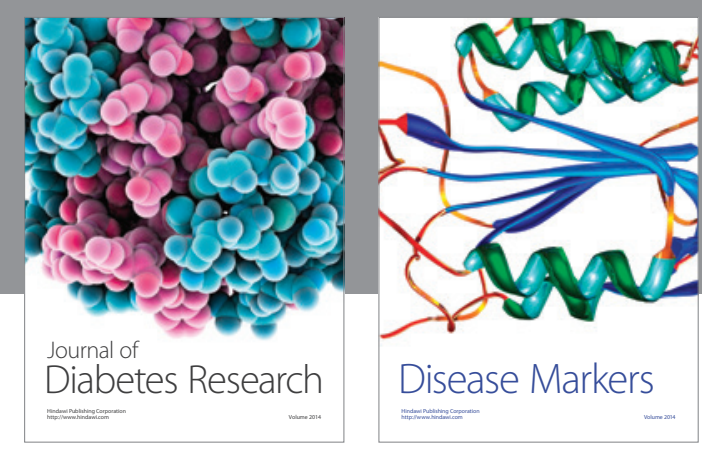

Disease Markers
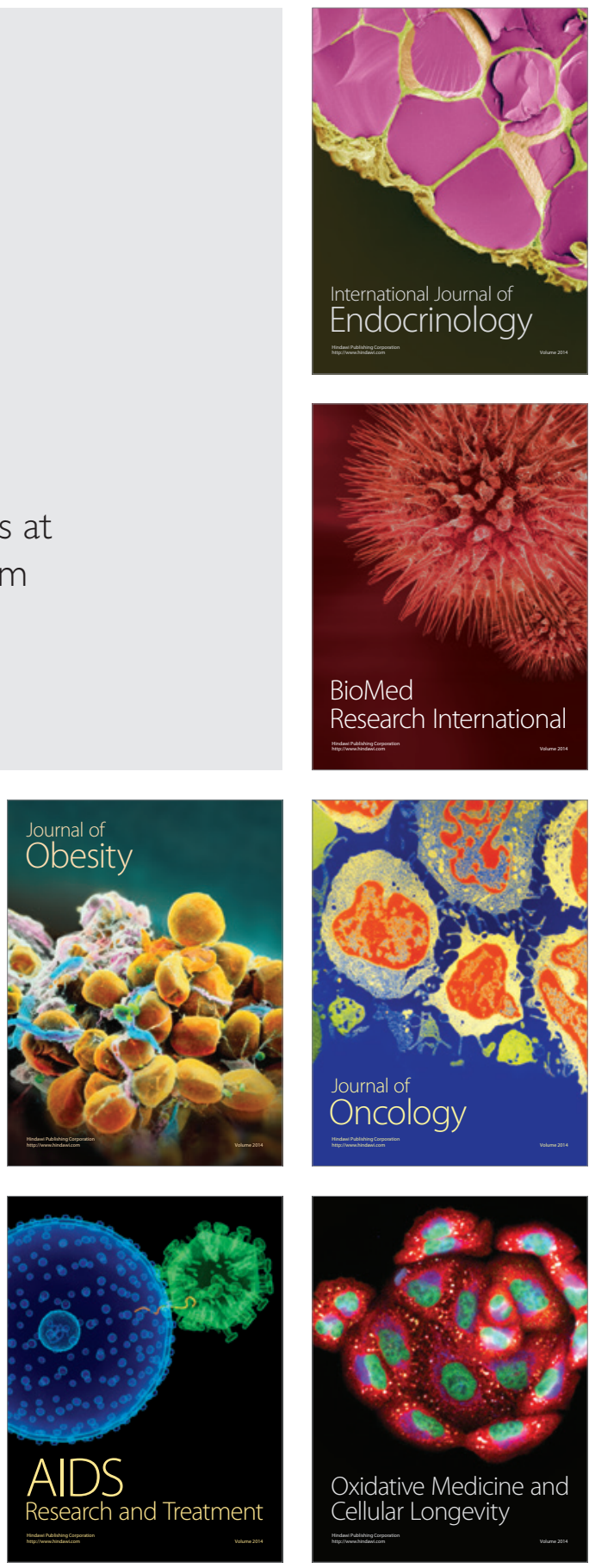